\title{
Letters
}

Website: www.bmj.com

Email: letters@bmj.com

\section{Public sponsors must follow ethical rules too}

EDitor-Bero's editorial on commercial sponsorship for research is important ${ }^{1}$ because commercial interests can bias the conduct and reporting of research. ${ }^{2}$ It may, however, leave the impression that pressure on research is an issue only in relation to commercial sponsorship.

I used to believe that public sponsors would allow the independent conduct of research, but experiences have taught me otherwise. Recent stories in the Norwegian mass media indicate that public sponsors may also breach ethical codes for research sponsorship. Newspapers have told their readers that the ministry of education tried to influence research into the effects of an educational reform, ${ }^{3}$ while a trade union tried to keep secret a report on privatisation of municipal services. ${ }^{4}$ The National Council of Tobacco and Health asked a research team to change its methods for analysing the economic consequences of smoking: the methods had been agreed on before the project started, but the council later asked the team to switch to a method that would make smoking seem more "costly" to society. In the end, the funding was stopped.

\section{Advice to authors \\ We prefer to receive all responses electronically, sent either directly to our website or to the editorial office as email or on a disk. Processing your letter will be delayed unless it arrives in an electronic form. \\ We are now posting all direct submissions to our website within 24 hours of receipt and our intention is to post all other electronic submissions there as well. All responses will be eligible for publication in the paper journal. \\ Responses should be under 400 words and relate to articles published in the preceding month. They should include $\leqslant 5$ references, in the Vancouver style, including one to the BMJ article to which they relate. We welcome illustrations. \\ Please supply each author's current appointment and full address, and a phone or fax number or email address for the corresponding author. We ask authors to declare any competing interest. Please send a stamped addressed envelope if you would like to know whether your letter has been accepted or rejected. \\ Letters will be edited and may be shortened. \\ www.bmj.com \\ letters@bmj.com}

For all three cases, the sponsors denied any unethical conduct.

Industry's motive for influencing research is obvious (profit), but the motives of public sponsors may be obscure. The perceived benefits from getting the "right" results are probably related more to organisations or interest groups than to individuals. Conceivably, civil servants or other parties see themselves as agents for public interests that entitle them to influence research. In the commercial sector agents are more used to criticism for biased research and may be better aware of the ethical rules. Interestingly, some researchers say they feel less pressure when undertaking research for the pharmaceutical industry than for government.

It is in the interest of all to have unbiased conduct and reporting of research. The same ethical rules should apply for privately funded as well as for publicly funded research.

Ivar Sønbø Kristiansen associate professor, Institute of Public Health, University of Southern Denmark, Odense

N-0853 Oslo, Norway

ivarsk@online.no

1 Bero LA. Accepting commercial sponsorship. $B M$ 1999;319:653-4. (11 September)

2 Kristiansen IS. Interactions between physicians and drug industry. Between Scylla and Charybdis. Tidsskr Nor Laegeforen 1998:118:1228-33. (In Norwegian.)

3 Blichfelt JF, Deichmann-Sørensen T, Lauvdal T. Towards new regime for knowledge. Evaluation of the Reform 94. Organ(n) Oslo: Work Research Institute, 1998. (AFIs rapportserie No 7/98.) (In Norwegian.)

4 Kagge G. Holding back a FAFO report. Aftenposten 13 Oc 1998:32. (In Norwegian.)

5 Hultgren J. Denies attempting to cheat. Aftenposten 18 Apr 1999:8. (In Norwegian.)

\section{Guidelines on HIV prophylaxis must be implemented}

EDITOR-Duff et al's telephone survey of surgeons' and occupational health departments' awareness of guidelines on postexposure prophylaxis for hospital staff who had been exposed to HIV raised two points. ${ }^{1}$ Firstly, although surgeons are indeed at risk of percutaneous exposure to HIV, it should be reiterated that there is a risk for all junior doctors and healthcare workers. Secondly, there seems to have been no assessment within the survey of how local policies are actually implemented. The survey assumed that if the occupational health department had guidelines in place then staff involved in their implementation were fully aware of the details and that guidelines were followed to the letter.

We conducted a similar survey on guidelines for post-exposure prophylaxis in July 1998 and also found that there was poor awareness of local guidelines by all grades and specialties of junior doctors. ${ }^{23}$ Only $54 \%$ $(19 / 35)$ of doctors knew whom to contact in the event of a needlestick injury during the day, and just 20\% (7/35) knew whom to contact if the injury occurred out of hours.

Policies within occupational health departments were often not well implemented or were impractical. In 20\% (7/35) of cases, occupational health staff did not know which combination of drugs is recommended in standard situations. Just under a quarter $(8 / 35)$ of the policies required the junior doctor who had been injured to travel to another hospital's occupational health department during the day. If the injury occurred out of hours, $26 \%$ (9/35) required the doctor to travel to another hospital for advice or to obtain the prophylactic drugs. There was also great variation as to who should be contacted for advice and where the starter packs of post-exposure drugs for prophylaxis were kept.

The main conclusion of our study and that by Duffy et al is that there is a problem with the dissemination of the national guidelines. Clinical guidelines may be meticulously developed and well presented but they are useless if they are not successfully implemented. ${ }^{4}$ Recommendations need to be put in place and disseminated to the individuals who are at risk. All trusts have a responsibility to inform their doctors how to obtain advice and access to necessary treatment 24 hours a day. The importance of having these policies in place and ensuring that all doctors know how to obtain treatment was highlighted by the case in September 1998 in which substantial damages were awarded to a junior doctor who had been traumatised after a needlestick injury. ${ }^{5}$ If the situation had been better handled the case probably would not have succeeded.

Rachel U Sidwell senior house officer Department of Dermatology, Chelsea and Westminster Hospital, London SW10 9NH

James S A Green specialist registrar Department of Urology, Royal Free Hospital, London NW3 2QG

Vas Novelli consultant in paediatric infectious diseases Great Ormond Street Hospital, London WC1N 3JH

\footnotetext{
1 Duff SE, Wong CKM, May RE. Surgeons' and occupational health departments' awareness of guidelines on postexposure prophylaxis for staff exposed to HIV: telepostsurvey. BMJ 1999;319:162-3. (17 July.)
} 
2 Department of Health. Guidelines on post-exposure prophylaxis for health care workers occupationally exposed to HIV London: DoH, 1997

3 Sidwell RU, Green JSA, Novelli V. The management of occupational exposure to HIV-what actually happens? Communicable Disease and Public Health 1999 (in press).

4 Field M, Lohr K, eds. Guidelines for clinical practice: from development to use. Washington, DC: National Academy Press, 1992

5 Battley vs Ealing, Hammersmith, and Hounslow Health Authority [1998] (out of court settlement).

\section{Prevention of vertical transmission of HIV in South Africa}

\section{Findings probably do not apply to rest of} sub-Saharan Africa

EDITOR-Söderlund et al report the cost effectiveness of options available in South Africa to prevent the vertical transmission of HIV. ${ }^{1}$ I have concerns about the applicability of their findings (from an urban South African hospital setting) to the rest of subSaharan Africa. ${ }^{1}$ The paper's conclusion that the treatment is cost effective assumes that each child in whom seroconversion is prevented would otherwise have consumed substantial hospital resources.

From the figures in the paper, I calculate that at least $£ 0.33-1.73 \quad(\$ 0.50-2.60)$ per capita is spent just on HIV positive children aged under 1 in an average sub-Saharan country. This clearly does not apply to a country like Malawi, whose health expenditure is around $£ 2.70(\$ 4)$ per capita. This cost-benefit conclusion is not applicable to most of sub-Saharan Africa, where children with HIV infection are generally treated at home and at health centres. Altogether $70-80 \%$ of public health costs in most health systems are staff costs and the salaries of health workers; thus even in South Africa the postulated hospital health cost savings in the analysis could not be recovered to fund the additional drug costs.

Using the authors' figures, I calculate that the antiretroviral drugs alone ( $£ 59$ (\$89) (PETRA regimen) to £267 (\$400) (ACTGO76 regimen) per person treated) would cost an average sub-Saharan African country between $£ 0.59(\$ 0.89)$ and $£ 2.10$ (\$3.20) per capita to implement. This added cost does not include the cost of setting up and running testing and counselling facilities. This intervention represents more than the entire healthcare budget in many sub-Saharan countries. Its benefit would be on average 15 seroconversions prevented for every 500 births.

The 66 year average lifespan used for the calculation of cost per life year saved will not be realistic in South Africa as the epidemic spreads, nor is it correct to assume that orphaned HIV negative children have an average lifespan. Evidence suggests that the loss of parents (in this case due to HIV infection) affects the survival of newborn children.

My concern is that this analysis, which is possibly more relevant for middle income countries, may be used by donors to push sub-Saharan governments into piloting these costly and unsustainable interventions. This will lead to yet another high cost vertical programme putting further pressure on the fragile health infrastructure, which is not coping even with current demands. The danger is that the overall effect is to the detriment of the health systems and that the only real beneficiaries will be the drug companies receiving the donor funds, which would be better spent on the health system infrastructure.

Christian Gunneberg Save the Children Fund UK, health adviser

Salima, Malawi

1 Söderlund N, Zwi K, Kinghorn A, Gray G. Prevention of vertical transmission of HIV: analysis of cost effectivene of options available in South Africa. BMJ 1999;318:1651-6. (19 June.)

\section{Paper did not include as a factor} suboptimal effects that arise

EDITOR-Söderlund et al conclude that antiretroviral interventions are cost effective in preventing the vertical transmission of HIV in South Africa. ${ }^{1}$ Our experiences concerning the operational aspects of implementing antiretroviral therapy in a rural district of South Africa suggest that there are additional practical considerations in estimating the costs and benefits of such a programme.

We followed up a cohort of 369 antenatal women in Hlabisa district. The outcome of pregnancy was known for 327 women. Their estimated date of delivery, based on a history of their last menstrual period, was a poor predictor of their actual delivery date, with $26 \%$ delivering before 38 weeks' gestation and $18 \%$ over two weeks after term (SD 27 days) (figure). Most (81\%) did not register before 18 weeks, which precluded accurate ultrasound confirmation of dates. Altogether 93\%, however, registered for antenatal care before 34 weeks' gestation, which allowed sufficient time for the screening and counselling necessary to receive an antiretroviral intervention. Finally, $82 \%$ of deliveries were in the health facility but only $2 \%$ of the women delivering at home intended to do so, which precluded early identification of this group.

Estimates of benefits of antiretroviral intervention need to include as a factor the suboptimal effects of a shortened regimen caused by preterm or home delivery and

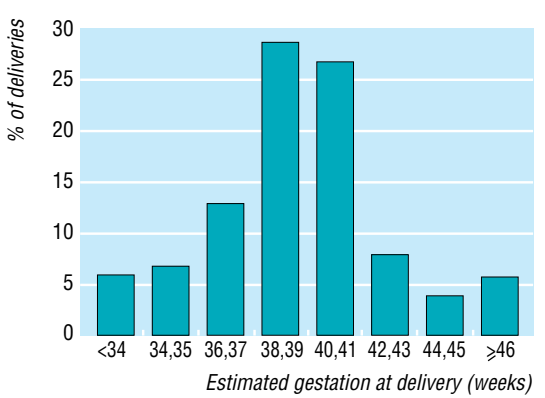

Distribution of gestational age at delivery based on history of last menstrual period extended costs in those delivering after term. The implementation of an antiretroviral intervention to prevent vertical HIV transmission is a desirable policy but must be accompanied by the necessary resources and not just become one more burden on the rural primary healthcare service.

K Rotchford senior scientist, Centre for Epidemiological Research South Africa (CERSA) rotchfok@mrc.ac.za

S S Abdool Karim director of CERSA

N Rollins project leader of the perinatal project

The Africa Centre, PO Box 198 Mtubatuba 3935,

South Africa

1 Söderlund N, Zwi K, Kinghorn K, Gray G. Prevention of vertical transmission of HIV: analysis of cost effectiveness of options available in South Africa. BMJ 1999;318:1650-6. (19 June.)

\section{Authors' reply}

EDITOR-Gunneberg is concerned about applicability of the findings of our study to other countries in sub-Saharan Africa. We do not recommend that the results are applied to settings different from the one studied. The sensitivity analysis in the original article deals with this issue to some extent by simulating circumstances different from the urban South African setting to which the model was applied. This cannot, however, replicate all possible scenarios (it is likely that many factors, not just healthcare spending, differ considerably between South Africa and Malawi). As we stated in the paper, we thus recommend that policymakers apply the model to their local circumstances, with a full set of local data to make a properly informed decision.

The model uses a 66 year average lifespan (current life expectancy at birth) to calculate the life years saved. We are aware that the life expectancy of children orphaned by AIDS may not be the same as that of those growing up in ordinary family settings but do not have quantitative data on this issue. Even if life expectancy dropped to 40 years, the overall model results would remain largely unchanged as a result of the effect of discounting more "distant" life years saved (PETRA regimen changes from $£ 9.33$ (\$14) to £10.66 (\$16) per life year saved). Clearly, the issue of raising children who have been orphaned because of AIDS in environments similar to those of other children-for example, by encouraging fostering and adoption with state incentivesrequires further study in its own right.

Gunneberg assumes that the interventions assessed would be implemented as a vertical programme. Our model costs the intervention as an add-on to existing antenatal care, and not as a vertical programme.

We agree with Rotchford et al that local practical constraints need to be considered before any intervention is implemented. However, with the newer short course regimens (such as the PETRA arm B and HIVNET 012 Nevirapine regimens), in which drugs are given during labour and after birth, late booking becomes a less important constraint. Non-eligibility for the intervention because of failure to use 
antenatal services does not fundamentally affect cost effectiveness, because the nonattending group consumes no resources related to the screening or the intervention.

Karen Zwi senior lecturer

Division of Community Paediatrics, Department of Paediatrics, University of the Witwatersrand, PO Box 1038, Johannesburg 2000, South Africa 092zwi@chiron.wits.ac.za

Neil Söderlund health economist

Centre for Health Policy, University of the

Witwatersrand

soderlun@icon.co.za

\section{Children were guaranteed regular check ups in dental study}

EDITOR-In the commentary on Uhari et al's trial of xylitol chewing gum in the prevention of acute otitis media White raised the problem of the ethical aspects of the study protocol because of the possible risk of caries in the control group. ${ }^{1}$ The objective of the trial was to see if regular use of xylitol chewing gum for two months would result in a reduction in the growth of Streptococcus pneumoniae causing acute otitis media, as had been the case in vitro. Children in the control group used sucrose chewing gum. The result was that the occurrence of acute otitis media was reduced by $40 \%$ but not the carriage rate of $S$ pneumoniae.

The dental healthcare system in Finland is such that a double blind, retrospective examination of the development of caries in the children who participated in the trial was possible. Dental records of each child involved in the trial (289 overall) were therefore analysed; 17 dropped out (eight from the xylitol group and nine from the sucrose group).

The number of decayed, missing, and filled primary and permanent teeth were calculated for the children in the year of the study (1995) and in 1997. The figures for the reference group were taken from the annual reports of Oulu Municipal Health Centre for 1995 and 1997. Slightly higher figures for decayed, missing, and filled primary and permanent teeth and slightly more new carious lesions were seen in the sucrose group, but the differences were not significant (table).

Dental health was also compared with a more sensitive system based on a survival analysis. ${ }^{2}$ The "birth" of a tooth was its recorded eruption into the oral cavity and "death" its recorded filling (due to dental caries). Recording was done at annual check ups, and we assumed that eruption and decay had both started a mean of six months earlier. The analysis was done with KaplanMeier curves for each tooth and tooth surface. ${ }^{23}$ No consistent difference between the study cohorts in the rate of decaying of any teeth was seen.

The fact that the Finnish municipal dental healthcare system guaranteed that children participating in the trial would have regular dental check ups was probably an important factor in the decision of the Finnish ethics committee to give permission for the trial. This decision was supported by the findings of the study, which found no increased risk of dental caries in the control group.

Vuokko Anttonen resident

Markku Larmas professor

Institute of Dentistry, Oulu University, 90220 Oulu, Finland

vanttone@cc.oulu.fi

Maarit Raitio chief dentist

Health Centre of Oulu, Oulu

1 Uhari M, Kontiokari T, Koskela M, Niemelä M. Xylitol chewing gum in prevention of acute otitis media: a double blind randomised trial [with commentary by $\mathrm{G}$ White] BMJ 1996;313:1180-4.

2 Virtanen J, Larmas M. Timing of first fillings on different permanent tooth surfaces in Finnish schoolchildren. Acta Odontol Scand 1995;53:287-92.

3 Larmas M, Virtanen J, Bloigu R. Timing of first restorations on permanent teeth, a new system for ora health determination. J Dent 1995;23:347-52.

\section{Use of iron pots in South Africa led to haemosiderosis}

Editor-Minerva writes about the cheap remedy of using iron pots for anaemic children in Ethiopia. ${ }^{1}$ Her suggested solution is not as simple as it may seem. South African indigenous people have been using iron pots for many years. The problem is that the pots are not only used for cooking; the fathers also use them for brewing their traditional beer. This beer has a low $\mathrm{pH}$ and dissolves the pot, giving a beverage full of iron. In South Africa the incidence of haemosiderosis in black people was the highest in the world. The condition even led to collapsed vertebrae due to a form of scurvy from the iron.

This siderosis is only now starting to disappear, as it is only about 25 years ago that
South African laws changed, allowing black people to buy the "white man's" liquor. Traditional brewing was no longer necessary, and the beer was brewed in factories and not in iron pots any more. We now see the siderosis only in people above the age of 50-60.

Good thought, Minerva, but bad in practice.

C F van der Merwe professor

Department of Gastroenterology, Medical

University of Southern Africa, Pretoria,

South Africa

tian@medunsa.ac.za

1 Minerva. BMJ 1999;318:746. (13 March.)

\section{Better evidence must be collected on childhood injuries}

EDITOR-The data presented by Sibert et al on preventing playground injuries are crucial for future evidence based interventions in injury prevention. ${ }^{1}$ Nevertheless, the primary step of collecting evidence, especially quality causal information, for paediatric injuries is still a major challenge. Despite the gradual development of surveillance centres in England, ${ }^{2}$ information on injuries still remains inadequate. In particular, reliable morbidity data that could be translated into preventive strategies are still rare in many areas. Kirklees, west Yorkshire, is one such area, and we report the paediatric fractures there.

We reviewed the hospital admission data after one of us (MGM) noticed an increased incidence of lower limb fractures with a long stay in the ward. Our study, from April 1996 to January 1999, focused on children aged 15. Altogether 109 children were admitted with lower limb fractures, caused by falls, sports, and road traffic accidents. Patients with fractured femur were admitted for long periods, costing the NHS $£ 6000$ per case. Admission rates were doubled, from 4 to 8 per 10000 children, in the youngest age group (0-4 years); the paediatric population was 41000 . This underpins the need to control paediatric accidents.

Data on risk factors such as ethnicity, socioeconomic status, and parental supervision were incomplete despite advances in computer systems. Information on preventable risk factors is lacking. ${ }^{.}$These data must

Mean (SD) numbers of decayed, missing, and filled permanent and deciduous teeth (DMF and dmf indices) in sugar and xylitol groups in 1995 and 1997

\begin{tabular}{|c|c|c|c|c|c|c|c|c|}
\hline \multirow[b]{3}{*}{ Year of birth } & \multicolumn{3}{|c|}{ Sugar group } & \multicolumn{3}{|c|}{ Xylitol group } & \multicolumn{2}{|c|}{ Reference group* } \\
\hline & \multirow[b]{2}{*}{$\mathrm{n}$} & \multicolumn{2}{|c|}{ Mean (SD) DMF/dmf } & \multirow[b]{2}{*}{$\mathrm{n}$} & \multicolumn{2}{|c|}{ Mean (SD) DMF/dmf } & \multicolumn{2}{|c|}{ Mean (SD) DMF/dmf } \\
\hline & & 1995 & 1997 & & 1995 & 1997 & 1995 & 1997 \\
\hline 1988 (DMF) & 32 & $0.09(0.39)$ & $0.34(0.83)$ & 39 & $0.31(0.83)$ & $0.51(1.07)$ & 0.46 & 0.47 \\
\hline 1989 (DMF) & 24 & $0.00(0.00)$ & $0.08(0.28)$ & 30 & $0.00(0.00)$ & $0.10(0.40)$ & 0.22 & 0.24 \\
\hline 1992 (dmf) & 22 & $0.18(0.85)$ & $0.55(0.85)$ & 14 & $0.00(0.00)$ & $0.21(0.58)$ & 0.11 & 0.65 \\
\hline \multicolumn{9}{|c|}{ No (\%) of children who developed caries (1-3 lesions) during follow up, with difference between percentages $(95 \% \mathrm{Cl}) \dagger$} \\
\hline 1988 & \multicolumn{3}{|c|}{$32(18.8)$} & \multicolumn{3}{|c|}{$39(12.8)$} & \multicolumn{2}{|c|}{$5.9(-11.2$ to 23$)$} \\
\hline 1992 & \multicolumn{3}{|c|}{$22(22.7)$} & \multicolumn{3}{|c|}{$14(14.3)$} & \multicolumn{2}{|c|}{$8.4(-16.9$ to 33.8$)$} \\
\hline
\end{tabular}

${ }^{*} \mathrm{n}=2828$ in 1995 and $\mathrm{n}=3559$ in 1997. †Sugar minus xylitol group. 
become part of the hospital information system. These requirements as well as the future research needs for injury prevention should be addressed in the planned amalgamation of Read codes and the systematised nomenclature of medicine (SNOMED) in NHS information systems.

Our hospital data are useful in profiling major fractures in the region where no surveillance centres are active. These could inform future regional preventive schemes. Three areas merit attention.

Firstly, a cohesive strategy, with a leading part played by regional surveillance centres, should be developed to collate existing data on paediatric injuries. Occasional reports are produced, ${ }^{45}$ but, even though organisations invest substantial resources in gathering this information, it is not collated so that an up to date and detailed profile of paediatric injuries is produced. The regional health authorities could play an active part in this.

Secondly, safety networks and effective interventions for paediatric injuries should be promoted. These are crucial for partnerships with primary care groups and recent NHS reforms and could be encouraged by national organisations such as the Child Accident Prevention Trust.

Finally, healthcare professionals and local communities should identify evidence based strategies from existing information on injuries, for the health and safety of children.

T T Ohn clinical assistant (research)

M G Miller consultant paediatrician

Huddersfield Royal Infirmary, Huddersfield

HD3 3EA

G Sparks head of department

Behavioural Science Department, Huddersfield

University, Huddersfield HD1 2DH

ttun6@hotmail.com

Competing interests: Dr Miller is chairperson and the other authors are members of Kirklees Child Safety Group, Kirklees, West Yorkshire.

1 Sibert JR, Mott A, Rolfe K, James R, Evans R, Kemp A, et al. Preventing injuries in public playgrounds through partnership between health services and local authority: community intervention study. BMJ 1999;318:1595. (12 June.)

2 Stone DH, Morrison A, Ohn TT. Developing injury surveillance in accident and emergency departments. Arch Dis Child 1998:78:108-10.

3 Aynsley-Green A, Jarvis SN, Roberts I, Towner EML. BailAynsley-Green A, Jarvis SN, Roberts I, Towner EML. Bail-
liere's clinical paediatrics: international practice and research. Unintentional injury in childhood and adolescence research. Unintent $1997 \cdot 5 \cdot 373-92$.

4 Walsh SS, Jarvis SN, Towner EM, Aynsley-Green A. Annual incidence of unintentional injury among 54000 children. Injury Prev 1996;2:16-29.

5 Department of Trade and Industry. Home acciden surveillance system. Annual report 1995. London: DTI, 1997.

\section{Japanese government should also ban tobacco advertising}

EDITOR-I was interested to read that the UK government has brought in regulations to ban tobacco advertisements. ${ }^{1}$ In contrast, the Japanese government helps tobacco companies to promote cigarettes. Although Japan Tobacco, Japan's former monopoly, was privatised in 1985, the Ministry of Finance still owns $70 \%$ of the company's stock.
According to a newspaper, ${ }^{2}$ Japan Tobacco has agreed to purchase the international portion of RJR Nabisco Holdings' tobacco business for $940 \mathrm{bn}$ yen (£4.74bn, $\$ 7.83 \mathrm{bn})$ to become the world's third largest tobacco producer. Japan Tobacco's various businesses now cover pharmaceuticals, food, and real estate. Several years ago it marketed a new drug (azasetron hydrochloride, a $5-\mathrm{HT}_{3}$ antagonist), which is effective against nausea and vomiting caused by anticancer chemotherapy. ${ }^{3}$ It has made a profit on sales of carcinogenic substances and then made money from the victims. Last December it tied up with a high technology company in the United States to develop a new gene therapy technique for treating prostate cancer and lung cancer.

In June this year another American bioscience research company announced that it would develop a new vaccine for lung cancer in conjunction with Japan Tobacco. It seems that Japan Tobacco wants more money from the victims of tobacco. The Japanese government should pressure Japan Tobacco to separate its pharmaceutical division; I hope that it follows the UK government's example.

Hiroshi Kawane associate professor

Department of Medicine, Kawasaki Medical School, Kurashiki City, 701-0192, Japan

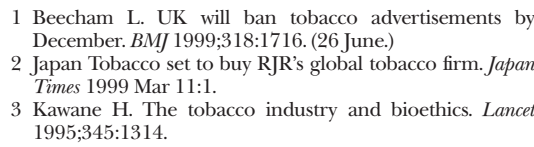

\section{Automatic replies can be sent to unsolicited email from general public}

EDITOR-Unsolicited email from patients and relatives asking for help is becoming a problem to regular medical internet users. Solicited email may well lead to an avalanche of unsolicited email, which might cause medicolegal problems for surgeons. We are still learning how we will control solicited email and videoconferencing requests from patients and the information overload problems that this will create. To attempt to "control" unsolicited email and indemnify ourselves I suggest that for every unsolicited email for advice this reply could be sent:

"I am sorry but I cannot answer unsolicited medical questions sent from patients or relatives to me either by email or through my website. Clinical advice must be obtained from your general practitioner or surgeon. Unsolicited email asking for medical advice, surgical or physician referrals, and sources of medical information will not be answered."

The General Medical Council of the United Kingdom (http://www.gmc-uk.org) has given the following advice to doctors in relation to email consultations:

"There are problems in providing email consultations because: $(a)$ the doctor asked to discuss email cases will not know the patient's full details; (b) not all facts, including the findings from a physical examination of the patient and the medical history, may be known; $(c)$ there will be no provision for the monitoring of a case or follow up care.

"We would recommend other surgeons in a similar situation consider using an email reply statement like this to unsolicited email."

Doctors may wish to adapt this statement depending on their local conditions.

Christopher Oliver consultant trauma and orthopaedic surgeon

Edinburgh Orthopaedic Trauma Unit, Royal Informary of Edinburgh, Edinburgh EH3 9YW c.woliver@edac.uk

1 Pal B. Email contact between doctor and patient. $B M J$ 1999:318:1428. (22 May)

\section{Suicide within 12 months of contact with mental health services}

\section{Local data vary from national data}

EDITOR-Appleby et al's paper on suicide and contact with mental health services has limitations compared with local data. ${ }^{1}$

A suicide audit team has existed in City and Hackney Community Services NHS Trust since 1995 and gathers information on sudden unexpected deaths of local residents from coroners' inquests and hospital records. We have difficulties because local coroners do not return information because of resource pressures. Local data were not returned to the national mortality programme on drug related deaths, ${ }^{2}$ and we are concerned that the national confidential inquiry into suicide and homicide by people with mental illness may have experienced similar problems. ${ }^{3}$ Complex boundary issues in east London and a high density, highly mobile population make psychiatric contacts difficult to trace, and hospitals' patient information databases are inaccurate: fewer than half the people on whom the team collects inquest data are registered as dead

We identified 84 unexpected deaths in two years. For 12 the coroner's verdict was suicide or equivalent, and for 30 it was an open verdict. Collating available information on these 42 deaths (suicide by Appleby et al's method), we judged 27 to be probable suicide and two to be due to drug and alcohol overdoses; in 13 cases the cause of death was "unascertained." We identified eight further deaths as probable suicides, although the coroner's verdict was misadventure or accidental death. For example, a 29 year old woman died from an overdose of tricyclic antidepressants and alcohol and left an explicit suicide note but a verdict of misadventure was given. This produces a classification discrepancy of 23 cases between the methods used by the local team and the national confidential inquiry.

Among suicides that would have been identified by the national confidential inquiry, 9 of the $42(21 \%)$ people who committed suicide had contact with local 
psychiatric services in the 12 months before death. When suicide is recorded by our more intensive method, however, the figure rises to 14 out of $34(41 \%)$, a considerable increase that may identify more information for prevention strategies.

The pattern of methods of suicide in east London is unusual. We have no recorded deaths by carbon monoxide poisoning, reflecting the fact that this is an area of low car ownership and lacks private parking. Of the methods chosen by people in contact with psychiatric services, violent methods accounted for 11 out of $14(79 \%)$ suicides.

These findings highlight both the difficulty of applying national trends to local areas and the problems of data collection for this difficult subject.

Alison Lowe consultant psychiatrist St Ann's Hospital, London N15 3TH alison.lowe@haringey-healthcare.thenhs.com

Emma Heap consultant psychiatrist

Stirling Moorey consultant psychiatrist

Homerton Hospital, London E9 6SR

1 Appleby L, Shaw J, Amos T, McDonnell R, Harris C, McCann K, et al. Suicide within 12 months of contact with mental health services: national clinical survey. $B M J$ 1999;318:1235-9. (8 May)

2 Ghodse H, Clancy C, Goldfinch R, Oyefeso A, Pollard M, Corkery J. National programme on substance abuse deaths. London: Centre For Addiction Studies, St George's Hospital Medical School, 1999. (Surveillance report No 2.)

3 Appleby L, Shaw J, Amos T, McDonnell R, Kieran K, Davies S, et al. Safer services. Report of the national confidential inquiry into suicide and homicide by people with mental illness. London: Stationery Office, 1999.

\section{Elderly people should be regarded as separate group}

EDITOR-Appleby et al believed that at least a fifth of suicides could be prevented by measures such as improving compliance and preventing loss of contact with mental health services. ${ }^{1}$ The importance of the study is unquestionable, but we are surprised that the national survey did not make any effort to consider elderly people--those over 65-separately.

Elderly patients with stroke have a significant increase in the risk of suicide, ${ }^{2}$ and a high rate of antidepressant treatment has been found in elderly people who commit suicide. ${ }^{3}$ This national survey found that alcohol and drug misuse were common among people who commit suicide, but this particular finding does not reflect the real picture in the case of elderly people who commit suicide. Community surveys such as the epidemiological catchment area study have estimated the proportion of alcoholic elderly people to be under $2 \%$ for men and under $1 \%$ for women. ${ }^{4}$ Appleby et al found that $15-18 \%$ of those who committed suicide were psychiatric inpatients at the time of death, but if elderly people are considered as a separate group this percentage will be much lower. The high percentage of people with a history of self harm does not apply to elderly people who commit suicide. Social isolation and physical impairment seem to be important risk factors in elderly people, but not to the same extent as in younger adults.

The risk factors for suicide in elderly people are fundamentally different from those in younger adults. Thus the measures that should be used to reduce suicide in elderly people will differ completely from those that could be useful in younger adults. In the case of elderly people, improving their social living conditions should probably have precedence over any other measures in order to reduce their suicide rate. We agree with Geddes that more research is needed into suicide, ${ }^{5}$ but we believe that elderly people should be regarded as a separate group.

George Tadros specialist registrar in old age psychiatry

Little Bromwich Centre, Northern Birmingham Mental Health Trust, Birmingham B9 5SF

Emad Salib consultant in old age psychiatry

Hollins Park Hospital, Warrington WA2 8WA

1 Appleby L, Shaw J, Amos T, McDonnell R, Harris C McCann K, et al Suicide within 12 months of contact with mental health services: national clinical survey $B M J$ 1999:318:1235-9. (8 May)

2 Stenager EN, Madsen C, Stenager E, Boldsen J. Suicide in patients with stroke: epidemiological study. BMJ 1998 , patients with

3 Waren M, Beskow J, Runeson B, Skoog I. High rate of antidepressant treatment in elderly people who commit suicide. $B M J$ 1996;313:1118.

4 Holzer CE, Myers JK, Weissman MM, Tischler GL, Leaf PJ Antecedents and correlates of alcohol misuse an dependence in elderly. In: Maddox GL, Robins LN, eds. The nature and extent of alcohol problems among the elderl. Bethesda, MD: Institute on Drug Abuse Researc 1984:84-1321. (NIAAA Research Monograph No 14.) 5 Geddes J. Suicide and homicide by people with mental illness. BMJ 1999;318:1225-6. (8 May.)

Rural and suburban populations can have more contact with mental health services

EDITOR-Are the suicide statistics of suburban and rural psychiatric services really worse than those elsewhere? Appleby et al have published statistics for completed suicide for England and Wales ${ }^{1}$ in the same week as Douds and Bridges present the suicide figures for the Fife region of Scotland. The figures are strikingly different.

In Fife, in $40(54 \%)$ of the 74 suicides recorded by the procurators fiscal in 1995-6 the person who committed suicide was known to the psychiatric services. Eighteen of the 40 had been seen by a psychiatrist in the previous 20 weeks, and 11 of the 40 in the previous month. If there was a cluster of suicides in a short period the figures would seem much worse and could lead to concern, even an inquiry. Appleby et al's figures show that in England and Wales only $24 \%$ of people who committed suicide were in contact with mental health services in the year before death but there was a variation between districts from $14 \%$ to $36 \%$.

In England and Wales (population 49 million) 6682 suicide verdicts (13.6 100000 ) were notified to Appleby et al during 1996-8; in Fife (population 350 000) there were 404 during 1985-94 (11.5/ 100000 ).

The most likely explanation of the suicide figures for Fife mental health services is that the rural and suburban population is more stable and therefore better known to their general practitioner, who has easy access to the area psychiatrist. In contrast, the figures for England and Wales would be weighted by conditions specific to the inner cities, whose psychiatrists are mostly working in a psychosis service serving the schizophrenic popula- tion that has drifted into the city. Psychiatrists in inner cities cannot offer treatment to patients with depression, alcoholism, and other more severe neuroses and who may not have a general practitioner. In Fife there has therefore been more contact with the local psychiatric services by people who eventually commit suicide.

The slightly lower overall suicide rates in Fife (11.5 $v 13.6 / 100000)$ may represent the best that psychiatry has to offer today and may hide many months or years of delayed suicide and enjoyed life because of treatment. Geddes notes, however, that "systematic reviews have found that no interventions have reliably been shown to prevent suicide or, indeed, deliberate self harm."

Appleby et al may have the data to confirm or disprove this hypothesis, which would be useful to anyone asked to conduct an inquiry into apparently bad suicide statistics from a suburban or rural district psychiatric service.

M D Beary consultant psychiatrist

Grovelands Priory Hospital, London N14 6RA Mikebeary@aol.com

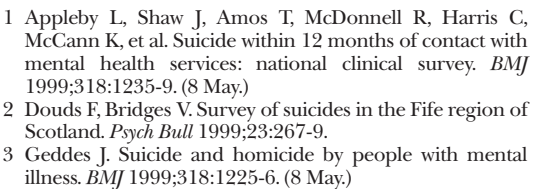

1 Appleby L, Shaw J, Amos T, McDonnell R, Harris C McCann K, et al. Suicide within 12 months of contact with mental health services: national clinical survey. $B M J$ 1999;318:1235-9. (8 May.)

2 Douds F, Bridges V. Survey of suicides in the Fife region of Scotland. Psych Bull 1999;23:267-9.

3 Geddes J. Suicide and homicide by people with mental illness. BMJ 1999;318:1225-6. (8 May.)

\section{Authors' reply}

EDITOR-In commenting on the national confidential inquiry report on suicide and homicide $^{1}$ that accompanied our recent papers ${ }^{2}{ }^{3}$ Geddes does not accurately report what it says. ${ }^{4}$ He devotes a detailed section of his editorial to the view that specific prevention measures would be a waste of resources because suicide and homicide are rare outcomes, but this argument does not apply if the same measures have other, much wider, benefits. As our report says, "In the relative absence of specific suicide and homicide prevention measures, the activities that are required-closer supervision, maintenance of treatments, etc-are in fact aspects of high quality care [and] many of the most needy patients will receive a better service." The aim of our recommendations is to strengthen services as a whole

Geddes is also critical because we are prepared to make recommendations without the evidence of clinical trials, but this is precisely the point. It is the absence of clinical trials that makes it necessary to use other forms of evidence, as confidential inquiries in other specialties have done with benefit Not that the evidence we quoted was flimsy. For example, we found that in a quarter of suicides of inpatients there were problems observing patients because of ward design, and we recommended that wards should remove any physical obstructions to observation. We found that a quarter of community patients who committed suicide or homicide were not taking their drugs in the previous month and recommended measures to improve compliance with treatment. These are hardly giant leaps of supposition. 
The letters about our paper raise issues that need to be clarified. The inquiry does not receive information directly from coroners, so we are not affected by the local problems to which Lowe et al refer. Although it is true that different definitions of suicide can be used in research, our definition is the one used by the Office for National Statistics when it publishes national suicide rates. The increased rate of case ascertainment in Lowe et al's study arises entirely from their including some cases of misadventure and accidents rather than from problems in identifying contacts with services.

Suicide by elderly people with mental illness is certainly important, as Tadros and Salib say; this may well be a future priority group for the inquiry. We expect them to differ from our all-ages sample, but there will also be similarities that these authors do not expect. For example, 12\% of our subjects aged over 65 were inpatients; $15 \%$ had a history of alcohol misuse.

Unfortunately, Beary has misunderstood our figures. The total of 6682 suicides is a two year sample, and the suicide rate is less than that in Fife, not more. Eighteen of the 74 people who committed suicide in Fife had had recent contact with mental health services $-24 \%$, exactly the same as our figure.

Louis Appleby director

Jenny Shaw assistant director

National Confidential Inquiry into Suicide and Homicide by People with Mental Illness,

Department of Psychiatry, Withington Hospital,

Manchester M20 8LR

Louis.Appleby@man.ac.uk

1 Appleby L, Shaw J, Amos T, McDonnell R, Kiernan K, Davies S, et al. Safer services. Report of the national confidential inquiry into suicide and homicide by people with mental illness. London: Stationery Office, 1999.

2 Appleby L, Shaw J, Amos T, McDonnell R, Harris C, McCann K, et al. Suicide within 12 months of contact with mental health services: national clinical survey. $B M$ J 1999;318:1235-9. (8 May.)

3 Shaw J, Appleby L, Amos T, McDonnell R, Harris C, McCann K, et al. Mental disorder and clinical care in people convicted of homicide: national clinical survey $B M J$ 1999;318:1240-4. (8 May.)

4 Geddes J. Suicide and homicide by people with mental illness. BMJ 1999:318:1225-6. (8 Mav.)

\section{Cochrane reviews will be in Medline}

EDITOR-Erny and Maradit-Kremers (and the editor in his reply to their letter) note some difficulties caused by the fact that Cochrane reviews are not indexed in Medline. This has made it difficult for people to identify these maintained systematic reviews and to keep track of them. We agree that this is a problem for anyone wishing to have access to up to date evidence of the effects of different healthcare interventions. Fortunately, this is set to change shortly as Cochrane reviews will soon be indexed in Medline. In addition, whenever a Cochrane review is updated substantively a record for the new version will be added to Medline with a reference to the earlier record.

In connection with this we are working within the Cochrane Collaboration to ensure that the impact of any updating of a Cochrane review is more transparent when the revised version is published in the Cochrane Library. ${ }^{2}$ It would be helpful if all systematic reviewers could ensure that they inform readers if their review has been published elsewhere. This is already the case with Cochrane reviews, where details are given of other published versions within each review.

We would encourage anyone preparing guidelines for the reporting of systematic reviews to urge that reviewers are explicit about the existence of other versions. We have struggled for some time with the problems caused by the multiple publication of randomised trials without appropriate cross referencing;; as reviewers we should ensure that we do not set the same traps for users of our research.

It would be helpful if journals could develop a mechanism by which readers are made aware of updated versions of any research that the journals have published. The advent of electronic forms of the journals will facilitate this. It needs to be made much easier for readers and users of medical research to identify the most up to date description and findings of that research.

Mike Clarke associate director (research) UK Cochrane Centre, Oxford OX2 7LG mclarke@cochrane.couk

Andy Oxman chair, Cochrane Collaboration Steering Group

Health Services Research Unit, National Institute of Public Health, Postboks 4404 Torshov, Oslo N-0403, Norway

1 Erny S, Maradit-Kremers H. What is publication? BMJ 1999;319:317-8. (31 July.)

2 Clarke M, Oxman AD, eds. Cochrane reviewers' handbook 4.0 [updated July 1999]. In: Review manager (RevMan) Computer program], version 4.0. Oxford: Cochran Collaboration, 1999.

3 Gotzsche P. Multiple publication of reports of drug trials Eur J Clin Pharmacol 1989;36:429-32.

\section{Searching for reliable research evidence need not be difficult}

Editor-Samanta and Beardsley summarise their search for and use of research evidence to inform their treatment of a patient with low back pain due to sciatica that did not respond to conservative treatment. ${ }^{1}$ They are to be applauded for their explicit and conscientious use of research, but we are surprised by their method of searching for relevant systematic reviews and trials.

Instead of searching Medline they could have accessed the relevant data more rapidly and directly by searching the Cochrane Library. This CD Rom contains a suite of databases including the Cochrane Database of Systematic Reviews-systematic reviews carried out under the auspices of the Cochrane Collaboration, abstracts of quality appraised systematic reviews (DARE) prepared by the NHS Centre for Reviews and Dissemination, and probably the world's largest register of controlled clinical trials.

A search of the Cochrane Library 1999 issue 2 using the single term "sciatica" identifies two completed Cochrane reviews and six protocols for systematic reviews. The review of surgery for lumbar disc prolapse concludes that chemonucleosis is more effective than placebo and that it is less invasive but also less effective than discectomy. ${ }^{2}$ The DARE database has references to several other reviews, which come to similar conclusions. In addition there were reviews of the effects and side effects of epidural steroids; although supporting the general safety of this treatment, they are less confident about its longer term benefits. ${ }^{3}$ There are also 105 trials identified in the controlled trials register, several published in the past few years.

Increasingly we would recommend a more efficient strategy for identifying systematic reviews and clinical trials which starts with a search of the Cochrane Library and Best Evidence ${ }^{4}$ and, since its recent launch, Clinical Evidence. ${ }^{5}$ Only if this strategy does not identify relevant and useful material is it worth investing the considerable time that can be needed to carry out a search of Medline and retrieve the relevant papers.

Trevor A Sheldon professor

Department of Health Studies, University of York, York YO10 5DD tas5@york.ac.uk

Julie Glanville information manager NHS Centre for Reviews and Dissemination, University of York, York YO10 5DD

1 Samanta A, Beardsley J. Sciatica: which intervention? BMJ 1999;319:302-3. (31 July.)

2 Gibson JNA, Grant IC, Waddell G. Surgery for lumbar disc prolapse. In: Cochrane Review. Cochrane Library. Issue 2. Oxford: Update Software, 1999

3 Abram SE, O'Connor TC. Complications associated with epidural steroid injections Regional Anesthesia 1996;21:149-62.

4 Glanville J, Haines M, Austin I. Finding information on clinical effectiveness. BMJ 1998:317:200-3.

5 Clinical evidence. London: BMJ Publishing, 1999.

\section{Screening of newborn infants for cholestatic hepatobiliary disease}

\section{Does test fulfil screening criteria?}

EDITOR-Mushtaq et al report their evaluation of a potential screening test for conjugated hyperbilirubinaemia in infants. ${ }^{1}$ Were this test to be considered in the implementation of a screening programme, however, several other issues would need to be considered along with the test itself.

The criteria of Wilson and Jungner, ${ }^{2}$ which have recently been updated and adopted by the national screening committee, are seen by many as the gold standard of screening assessment. ${ }^{3}$ Mushtaq et al do not overtly state the hypothesis that they are testing. They simply say that they wished to evaluate tandem mass spectrometry for the detection of conjugated hyperbilirubinaemia in neonates. Application of the Wilson and Jungner screening criteria before the study began would have highlighted any potential difficulties in a future screening programme regardless of the outcome of this feasibility study.

One of the most important criteria is that effective evidence based treatment and optimised treatment must be available for 
the condition being screened. Clearly this is not the case for conjugated hyperbilirubinaemia, which represents not a single disease but a host of conditions determined by an abnormal laboratory value. We recognise that there can be improved survival after surgery for biliary atresia, as the authors state, but whether the rates of success of only $30-50 \%{ }^{4}$ merit setting up a screening programme is arguable.

The authors state that identifying patients with increased bilirubinaemia allows vitamin $\mathrm{K}$ to be given to reduce the high level of bleeding disorders in this group. In our experience vitamin $\mathrm{K}$ is routinely given to neonates, so the implementation of tandem mass spectrometry would not be justified for this purpose.

We believe that the effect of proposed actions to improve the variables in future assessment by taking the sample at 14 days and two hours after a feed would require the construction of a hypothesis examining the role of targeted blood testing rather than using available Guthrie cards. This brings us back full circle to the Yellow Alert campaign. ${ }^{5}$

Eithne Linnane specialist registrar in public health medicine

Ashish Paul specialist registrar in public health medicine

Ruth Parry consultant in public health medicine North Wales Health Authority, Mold, Flintshire CH7 1PZ

eithne.linnane@nwales-ha.wales.nhs.uk

1 Mushtaq I, Logan S, Morris M, Johnson AW, Kelly D, et al Screening of newborn infants for cholestatic heptobiliary disease with tandem mass spectrometry. [With commentary by A Berger.] BMJ 1999;319:471-7. (21 August.)

2 Wilson JMG, Jungner G. Principles and practice of screening for disease. Geneva: WHO, 1968. (Public health paper No 34.)

3 http://www.doh.gov.uk/nsc/chap61.htm (accessed 14 September 1999).

4 Okazaki T, Kobayashi H, Yamataka A, Lane GJ, Mivano T Long-term postsurgical outcome of biliary atresia. J Pediatr Long-term postsurg

5 Mowat AP, Davidson LL, Dick MC. Earlier identification of biliary atresia and hepatobiliary disease: selective screening in the third week of life. Arch Dis Child 1995;72:90-2.

\section{Authors' reply}

Editor-Linnane et al highlight the fact that conjugated hyperbilirubinaemia is "not a single disease but a host of conditions determined by an abnormal laboratory value." This, however, is no bar to screening, as evidenced by screening for phenylketonuria and screening for hypothyroidism. These programmes actually identify children with a variety of conditions with different prognoses and requiring different management. A great deal is known about the natural course, prognosis, and response to treatment of the individual disorders causing conjugated hyperbilirubinaemia. There is clear evidence of benefit from the early detection of the main target condition (extrahepatic biliary atresia), although the magnitude of the benefit remains less certain.

The issue with regard to giving vitamin $\mathrm{K}$ is not only whether the vitamin is given but also how it is given. ${ }^{1}$ Children with cholestatic liver disease do not absorb vitamin $\mathrm{K}$ adequately from the gut and are at particular risk of vitamin $\mathrm{K}$ deficiency bleed- ing. A small but important number of infants are not given vitamin $\mathrm{K}$ at birth, and many are given only a single dose of oral vitamin $\mathrm{K}$, which, particularly in children with liver disease, may not prevent serious haemorrhage. Each year a considerable number of such children have fatal or disabling haemorrhages.

The criteria used by the national screening committee in considering screening programmes (not screening tests) are designed to ensure that the benefits of the programme outweigh the harms. When proposed programmes clearly fall short of these standards they can be regarded as absolute criteria. For most proposed programmes, however, what is required is a quantitative assessment of the balance of risk and benefit. To carry out these modelling exercises, measures of test performance are needed. For this study, the statement of a hypothesis would not have been helpful as the aim was not hypothesis testing but estimation of test variables for a candidate test and assessment of the implications of applying such a test to the population.

Peter T Clayton professor of paediatric metabolic disease and hepatology

Stuart Logan director, systematic reviews training unit Institute of Child Health, London WC1N 1EH

1 Von Kries R. Oral versus intramuscular phytomenadione safety and efficacy compared. Drug Saf 1999;21:1-6.

\section{Earlier discharge for newborns may increase health risks}

EDITOR-Both findings reported in the news item on early discharge for newborn infants have been published previously. ${ }^{1}$ Kotagal et al studied 57 infants discharged in 1993 after the introduction of a clinical guideline encouraging early discharge. ${ }^{2}$ These were infants on a neonatal intensive care unit rather than infants born during uncomplicated term deliveries, but the reduction in mean length of hospital stay after the introduction of the early discharge programme varied from almost 30 days for infants under $750 \mathrm{~g}$ to 4.5 days for those weighing 2001-2500 g. The authors estimated that during the seven months of the study, 1817 days in total, or an average of seven days, were saved.

Lee et al, also working in Toronto, Ontario, showed that the length of the newborn stay for term infants decreased from 4.5 days in $1987-8$ to 2.5 days in $1993-4$. $^{3}$ Over the same period, however, the readmission rate per 1000 live births increased from $2 / 1000$ to almost $8 / 1000$. Many of these readmissions were for jaundice or dehydration, conditions that may previously have been avoided when infants stayed in hospital longer.

Since there is little new, this was not news.

Terence Stephenson professor of child health

School of Human Development, Academic Division of Child Health, Queen's Medical Centre,

Nottingham NG7 2UH
1 Spurgeon S. Earlier discharge for newborns may increase health risks. BMJ 1999;319:469. (21 August.)

2 Kotagal UR, Perlstein PH, Gamblian V, Donovan E Atherton HD. Description and evaluation of a program for the early discharge of infants from a neonatal intensive care unit. J Pediatr 1995;127:285-290

3 Lee K-S, Perlman M, Ballantyne M, Elliott I, To T. Association between duration of neonatal hospital stay and readmission rate. J Pediatr 1995;127:758-66.

\section{Do we need a new word for patients?}

\section{"Users" isn't an appropriate alternative}

Editor-Part of Tallis's response to Neuberger's idea of doing away with the word "patients" is to suggest that, if the debate is worth pursuing, the next step would be to research what people actually think about the word "patient."1 Although I'm certain that a small study in Australia will not be the last word on this particular word, might I draw attention to Nair's report last year in the Medical Journal of Australia? ${ }^{2}$ Nair studied 308 outpatients at John Hunter Hospital, Newcastle, New South Wales, and concluded that over four fifths of all patients approached, and over nine tenths of those aged over 60 , preferred the term patient to "client" or "customer"

The term "user" more commonly refers to users of injected drugs than to users of the health service and thus could lead to some interesting confusions over time should it be adopted.

Richard Thode project officer, oncology education committee Australian Cancer Society, Kings Cross, Sydney, NSW 2001, Australia

richardt@nswcc.org.au

1 Neuberger J, Tallis R. Do we need a new word for patients? BMJ 1999;318:1756-8. (26 June.)

2 Nair BR. Patient, client or customer. Med J Aust 1998; 169:593.

\section{Continue to call them patients but treat them like customers}

EdiToR-Neuberger's article reminds me that in 1993 I was chief executive of Royal Brompton Hospital in London. ${ }^{1}$ We had a healthy internal debate then about what name we should use for those people who came to the hospital when we became an NHS trust in the internal market. The decision was to call them patients but treat them like customers.

Here in Toronto, where I am now a governor of a hospital board, "client" is the term that hospital staff, including medical staff, have adopted.

William Bain vice president, corporate affairs MDS, Toronto, Ontario, Canada M9A 4C9 bbain@mdsintl.com

1 Neuberger J, Tallis R. Do we need a new word for patients? $B M J$ 1999;318:1756-8. (26 June.)

\section{Patients should obviously now be called "Neubergers"}

EDITOR-We need a word to replace "patient." Obviously, modesty forbids Neuberger from suggesting that henceforth patients should be known as "Neubergers." 
Neuberger thus eponymously described should therefore be on the same footing as past heroes of the medical profession, such as Parkinson, Addison, and of course the far seeing Argyll-Robertson.

I am sure that this would facilitate the interactive Neuberger centred health promoting consultations that will characterise the millennium. The word is euro-friendly, is refreshingly free from any taint of political incorrectness, and does not have the emotive associations of its predecessor. In these days of lifestyle option consultations, when my receptionist tells me that I have a surgery full of Neubergers awaiting me I shall know exactly what to expect.

Should this idea fail to gain acceptance, with some trepidation I offer the term "Bevanites," although I can't see this going down too well in the stockbroker belt.

Roger Stevens partner in practice Roborough Surgery, Roborough, Plymouth PL6 6PH

roboro@cwcom.net

1 Neuberger J, Tallis R. Do we need a new word for patients? BMJ 1999;318:1756-8. (26 June.)

\section{Both patients and doctors should be} known as actors

EDIToR-The debate on what to call the person at the blunt end of the stethoscope has more profound implications than the "regressive, reference-less data-free airing of opinion" that Tallis suggested. ${ }^{1}$ The lexicon both reflects and shapes the way that we construct the world around us, and Tallis showed clearly his entrapment within a modern, linear medical paradigm. Neuberger struggled unsuccessfully, overlooking the importance of the evolving context.

In the beginning the patient was clearly defined as the one who shut up and did as he or she was told by the doctor. The late 1970s saw the evolution of a more tenuous relation between health and health care; patient became client. In the early 1980s evidence based medicine began to call the shots and health care manipulated the odds against a background of inferential statistics; client became punter. The late 1980s saw a shift of emphasis to economics, with the purchaser-provider split reflecting the directives of the market; punter became consumer. In the late 1990s there is an evolving perspective of cooperation, with an emphasis on partnership in health; consumer becomes citizen.

But where for the next millennium? Complexity theory is beginning to unravel a picture that sees doctors and citizens as players tentatively performing on a complex non-linear stage. Perhaps Shakespeare and health economists were right all along. Both patients and doctors should be known as actors. ${ }^{2}$

David Kernick general practitioner St Thomas Health Centre, Exeter EX4 1HJ su1838@eclipse.co.uk

1 Neuberger J, Tallis R. Do we need a new word for patients? $B M J$ 1999;318:1756-8. (26 June)

2 Kernick DP. The name's the game. Lancet 1999;353:1632

\section{What's in a name, after all?}

EDIToR-To imply that the word patient is derogatory is a gross oversimplification born out of the farce of political correctness. ${ }^{1}$ The onus of finding a better name must rest with whoever started this silly debate, so that we can get on with our real jobs, which undisputedly should be to "cure sometimes, heal often, and comfort always."

If there is a doubt about the relationship between doctor and patient this is not because of a misinterpretation of the title patient; rather our role as medical professionals should be reanalysed on the basis of guidance from the "consumers" of our care. Perhaps in this modern era of litigationhappy patients we should be changing titles from doctor and patient to defendant and plaintiff.

If we are to promote choices for patients, as "users or consumers," do we really want this? Changing a title will not do this. Beware patients seeking out their versions of appropriate health care, who may be doctor shopping for antibiotics for an upper respiratory tract infection despite the previous doctor's attempts at education to the contrary; also beware the patient who chooses the prescription happy "diazepam prescriber" in preference to the "sleep hygiene instructing doctor." Consumerism has its pitfalls too.

If we are to respect our patients as people, clearly this is the responsibility and choice of the medical professional; any amount of force will not change this, least of all by changing the designation from patient to "person." Medical educators know well that you cannot change the personality of a medical student into society's vision of the ideal doctor.

To imply that as doctors we do not recognise our patients as people, or the heterogeneity of the patients who request our help, is nonsensical and must be addressed before a change in the title of patient is due. Any replacement title will no sooner have assumed its new designation before it too, in a meaningless battle, faces the same battle as that fought against its old rival.

Murat Acar trainee in rehabilitation medicine Westmead Hospital, Sydney, NSW, Australia murata747@hotmail.com

1 Neuberger J, Tallis R. Do we need a new word for patients? BMJ 1999;318:1756-8. (26 June.)

\section{GMC should just continue its} role as policeman and not try to improve clinical standards

EDITOR-Clinical governance bothers me. It reminds me of the chants we shouted in student days: "Who will police the police?"

Most doctors I know didn't go on student demonstrations, but I have two degrees. The first was a history degree, when we went on demonstrations against all sorts of things, and the second was a medical degree, when a demonstration was something that took place in the anatomy lecture theatre, and everyone was worried that if they didn't attend they might fail their exams; by contrast, arts students worried that if they didn't demonstrate they might fail society. I have two further qualifications on paper, the diploma of child health and membership of the Royal College of General Practitioners. Apparently this is not enough for Sir Donald Irvine, the president of the General Medical Council. It has to be publicly shown that I am still fit to practise more than 20 years after I qualified.

What worries me is that, in this so called evidence based era (as though previous generations needed little or no evidence about outcomes of treatments), we are being pushed into worshipping at the altar of management, while there is little evidence as far as I can see either that there is a major problem or that management, protocols, and so on are any guarantee of improvement in providing clinical care. I have yet to meet a doctor who deliberately kills patients, although I suppose that they exist. It is the primitive element of the mind that sees us all as Sweeney Todds, but nevertheless Sir Donald is leading us into a paranoid nightmare in which barber shop inspectors will be examining our instruments, checking our appointment systems, and seeing if a number one haircut in Aberdeen is precisely the same as a number one haircut in Truro.

This is a regression into seeing doctors as barber surgeons. This is what the Bristol case was all about. It is also a regression into seeing patients as statistics - a smearable woman, an injectable infant, a hypertensive, a diabetic, a transposition of the aorta. As I was preparing for my exams for membership of the Royal College of General Practitioners, and indeed my finals, I was encouraged to see patients as people, but I fear that clinical governance is likely to count them as statistics. I like good clinical records, but I know many doctors who thrive on Lloyd George envelopes, yet their patients do not seem to be dropping dead in their surgery carparks after each consultation.

The professional colleges should remain the educational establishments where we seek enlightenment and new ideas. The General Medical Council should stick to its role as policeman. In fact it needs reforming, like the House of Lords. At the moment it is a quasi-court, in which it acts as prosecutor, judge, and jury. Doctors pay for their own prosecution (via council fees) and for their own defence (via medical defence union fees). It is a strange system, and I do not think that the council is the right body to attempt to lead the way into better clinical standards.

Tony Walsh general practitioner The Surgery, Kents Hill, Milton Keynes MK7 6HQ

\section{Rapid responses $\quad e B M J$ Correspondence submitted electronically is available on our website www.bmj.com}

